\title{
A história de um evento esportivo entre continuidades e rupturas: as Olimpíadas Colegiais e os Jogos Colegiais do Paraná (1938-1953)
}

\author{
Isabel Cristina Martines*
}

Sérgio Roberto Chaves Junior ${ }^{* *}$

\begin{abstract}
Resumo: O presente artigo questiona determinada versão da história que indica o surgimento dos Jogos Colegiais do Paraná no início da década de 1950, confrontando a relação desse evento com as Olimpíadas Colegiais e Ginasiais, promovidas pelo Colégio Estadual do Paraná desde o final da década de 1930. A hipótese central do estudo é de que as competições esportivas, que já se faziam presentes nos estabelecimentos de ensino, receberam grande destaque em 1953, em virtude de uma série de configurações políticas, na tentativa de construção de um lugar de poder e de uma identidade esportiva pelo governo estadual.

Palavras-chave: Esportes. História. Educação Física.
\end{abstract}

\section{INTRODUÇÃO}

A motivação para a escrita deste artigo ${ }^{1}$ surgiu quando encontramos em pesquisas anteriores, realizadas em momentos e com preocupações distintos, a temática dos campeonatos esportivos envolvendo estudantes no estado do Paraná. Ao dirigir o olhar para tais trabalhos, percebemos certa discordância em relação ao início das competições esportivas nos estabelecimentos de ensino paranaenses e, com vistas a essa problemática, iniciamos nossa discussão.

Na primeira pesquisa em questão, Chaves Junior (2004) percebeu a crescente importância atribuída à educação física, ${ }^{2}$ principalmente $\mathrm{a}$

\footnotetext{
* Mestre em Educação Física pela UFPR. Pesquisadora do Centro de Pesquisas do Esporte, Lazer e Sociedade (CEPELS) da UFPR. Professora Assistente do Curso de Gestão Desportiva e de Lazer, Setor Litoral, UFPR, Matinhos, PR, Brasil. E-mail: belmartines@hotmail.com ** Mestre em Educação pela UFPR. Professor Assistente do Departamento de Teoria e Prática de Ensino (DTPEN), UFPR, Curitiba, PR, Brasil. E-mail: sergiojunior79@hotmail.com 1 Uma versão preliminar deste artigo foi apresentada no XVI Congresso Brasileiro de Ciências do Esporte (CONBRACE) / III Congresso Internacional de Ciências do Esporte (CONICE), realizado em setembro de 2009, em Salvador-BA.
} 
partir da década de 1930, culminando, entre outros fatores, com o processo de esportivização das aulas de Educação Física em um dos mais destacados estabelecimentos de ensino do estado, a saber, o Colégio Estadual do Paraná (CEP), representado pela construção das instalações esportivas do novo prédio do CEP, no início da década de 1950, a disponibilização de uma quantidade considerável de materiais, além da contratação de professores de Educação Física (STRAUBE, 1993).

Em meio ao processo de valorização dessa disciplina escolar, o autor aponta para o surgimento de competições esportivas envolvendo estudantes de uma série de instituições do ensino secundário paranaense. Uma destas competições, as Olimpíadas Colegiais, surge em 1938, sob a organização de alunos do ensino secundário e do professor José Heredia Navarro que, na época, ministrava aulas de Educação Física no CEP.

Por sua vez, a pesquisa de Martines (2007) trata das políticas públicas para o esporte escolar no estado do Paraná, analisando mais especificamente os Jogos Colegiais do Paraná. ${ }^{3}$ A autora indica que a primeira edição dos Jogos envolvendo os estudantes paranaenses aconteceu em 1953, na cidade de Curitiba, contando com a participação de 52 instituições de ensino. Sobre a realização da primeira edição dos Jogos Colegiais, Lester Pinheiro ${ }^{4}$ afirma que:

[...] em 1953, ano do Centenário de Emancipação Política do Paraná, alguns abnegados que observavam o contexto europeu, resolvem levar adiante um sonho - criar os Jogos Colegiais do Estado do Paraná. Sim,

\footnotetext{
2 Para além das diferentes grafias, os termos educação física e Educação Física são utilizados possuindo diferentes significados. Ao termo educação física é atribuída uma ideia mais ampliada de formação e cuidados com o corpo, uma ideia de educação do físico. Já o termo Educação Física é utilizado para se referir à disciplina escolar que, juntamente com outras disciplinas, é responsável pelo cuidado com o físico e com a educação física.

${ }^{3}$ A competição que atualmente recebe o nome de Jogos Colegiais do Paraná (JOCOPs) já foi denominada de Jogos Estudantis e Jogos Escolares. No ano de 2008, os JOCOPs chegaram "oficialmente" a sua $55^{\mathrm{a}}$ edição, na qual participaram aproximadamente 300 mil alunos de escolas públicas e particulares de todos os municípios paranaenses. Além disso, o evento recebe um dos maiores investimentos para o esporte no estado, que financia integralmente, entre outras coisas, a alimentação, o transporte e o alojamento para os alunos participantes da competição. Para maiores informações sobre os JOCOPs ver: http://www. paranaesporte.pr.gov.br, acesso em 15/09/2008.

${ }^{4}$ Quando a pesquisa foi realizada, Lester Pinheiro era diretor de esportes da Paraná Esporte, autarquia vinculada à Secretaria de Estado da Educação e responsável pela realização dos Jogos
} Colegiais do Paraná.

Movimento, Porto Alegre, v. 16, n. 01, p. 209-225, janeiro/março de 2010. 


\begin{abstract}
chamava-se originariamente Jogos Colegiais e, hoje, também são os Jogos Colegiais! Pontuam nesta época os Srs. Carlos de Almeida Assunção, Hugo Pilato Riva e Rubens Bartolomei Marchand. Estes senhores foram os verdadeiros responsáveis pela criação e manutenção dos Jogos Colegiais, durante várias décadas. A principal característica era a ênfase dada às bandas ou fanfarras, com suas balisas. Tratava-se de uma festa sensacional para os parâmetros da época. Já na $1^{\mathrm{a}}$ edição participavam mais de 3000 alunos (MARTINES, 2007, p. 40).
\end{abstract}

Corroborando a citação acima, também encontramos nos trabalhos de Mezzadri (2000) e Martins (2004) que os Jogos Colegiais iniciaram no ano de 1953. Não obstante, Mezzadri afirma que somente a partir da década de 1950

“[...] a prática esportiva, que antes se restringia aos clubes, começava a ser inserida pelo governo nos estabelecimentos de ensino, constituindo-se um dado significativo na formação dos alunos e passando a ser prioridade do governo" (MEZZADRI, 2000, p. 67).

Para o autor, a criação da Divisão de Educação Física, em 1951, foi um fator determinante para a institucionalização da prática das atividades esportivas nas escolas. Tal divisão, subordinada ao Departamento de Ensino da Secretaria de Educação e Cultura, teria a responsabilidade de orientar, dirigir e fiscalizar a Educação Física nos estabelecimentos de ensino do Paraná, além de difundir e incentivar a prática dos desportos educativos (MEZZADRI, 2000, p. 67).

A partir do exposto até aqui e tendo como ponto de partida alguns procedimentos que Thompson (1981) denominou de lógica histórica, chamamos a atenção para as seguintes questões: por que algumas fontes indicam que no final da década de 1930 as práticas e competições esportivas já se faziam presentes nas/entre as instituições escolares no Paraná e determinada literatura aponta o início das competições esportivas escolares no estado somente na década de 1950 ? Seriam os Jogos Colegiais do Paraná uma "continuidade" das Olimpíadas Colegiais, realizadas pelo Colégio Estadual do Paraná desde a década de 1930, ou os Jogos Colegiais de 1953 marcam uma "ruptura" com as competições realizadas até então?

Movimento, Porto Alegre, v. 16, n. 01, p. 209-225, janeiro/março de 2010. 


\section{Artifor Originais Isabel C. Martines e Sérgio R. C. Junior}

Em busca de possíveis respostas, partimos à procura de evidências históricas que apresentem alguns indícios das origens das práticas e competições esportivas nas escolas paranaenses e, mais especificamente, o início dos Jogos Colegiais do Paraná.

Como fontes, privilegiamos o Jornal do Colégio Estadual do Paraná e as Atas dos Jogos e Olimpíadas Colegiais, disponíveis no Centro de Documentação do Museu Guido Straube, localizado no Colégio Estadual do Paraná. Utilizamos ainda algumas edições do Jornal Gazeta do Povo que fazem parte do acervo da Divisão de Documentação Paranaense da Biblioteca Pública do Paraná.

A partir dessas considerações preliminares, apresentaremos num primeiro momento o surgimento das Olimpíadas Colegiais, iniciadas em 1938 e que se tornaram um tradicional "certame estudantil" entre as instituições escolares paranaenses ao longo das décadas de 1940 e 1950. Na sequência, trataremos do evento de 1953, que é apresentado em alguns trabalhos e na versão do governo estadual como a edição pioneira dos Jogos Colegiais, além de questões presentes nos eventos posteriores, em especial os ocorridos em 1954 e 1955. Por fim, buscaremos discutir os prováveis motivos que fizeram com que os Jogos realizados em 1953 fossem reconhecidos pelas "fontes oficiais" como um marco para o esporte estudantil paranaense.

\section{As Olimpíadas Colegiais do Colégio Estadual do Paraná: AS PRIMEIRAS INICIATIVAS ESPORTIVAS}

De início, cabe um registro importante para contextualização: em meados da década de 1930, além das reformulações de toda ordem em relação à Educação Física no ensino secundário paranaense e, em especial, no Colégio Estadual do Paraná (CEP), foi criada a Associação Ginasiana de Educação Física do CEP, que passaria a responsabilizar-se por todos os eventos esportivos da instituição de ensino.

Nos anos finais da mesma década, o então professor de Educação Física do CEP, José Heredia Navarro, foi procurado e incentivado por integrantes da Associação Ginasiana para organizar um campeonato esportivo entre os colégios do Paraná. O evento, que foi chamado de Olimpíadas Colegiais, contou, na sua primeira edição, em 1938, com

Movimento, Porto Alegre, v. 16, n. 01, p. 209-225, janeiro/março de 2010. 
a participação de algumas instituições de ensino secundário da cidade de Curitiba (O COLÉGIO..., 1954a). O CEP, à época, utilizava para a realização da competição, campos e quadras cedidos por diferentes clubes da capital paranaense, já que não possuía ainda espaços próprios para a prática esportiva.

Tendo o segundo certame estudantil sido realizado em 1939, nos mesmos moldes do primeiro, gostaríamos de fazer um destaque à terceira edição das Olimpíadas Colegiais, realizada entre os meses de setembro e outubro de 1940. O evento contou com a participação de sete estabelecimentos de ensino secundário da capital e um da cidade litorânea de Paranaguá, reunindo ao todo 268 atletas, competindo nas modalidades de futebol, voleibol, basquetebol, natação e atletismo. Nessa edição das Olimpíadas, aconteceu a primeira participação feminina, nas modalidades de voleibol, basquetebol e atletismo.

A preocupação demonstrada pelos alunos em organizar e participar de um evento como esse evidencia um crescente interesse nas questões relativas à prática esportiva dentre a juventude paranaense que frequentava o ensino secundário. As próprias aulas de Educação Física, em especial no CEP, começaram a ter como conteúdos algumas práticas esportivas, para além dos exercícios ginásticos que eram predominantes à época. Tal iniciativa, inclusive, foi tomada pelos próprios alunos, ao proporem a prática de modalidades esportivas, em especial, o futebol (CHAVES JUNIOR, 2004).

Para Linhales, "conteúdos ou práticas sociais quando transformados em conteúdos ou práticas escolares, remetem a uma necessária reflexão acerca das condições históricas e culturais que possibilitaram tal realização" (2006, p. 93). De acordo com a autora, os processos de transformação das práticas sociais em conteúdos escolares acontecem a partir de determinadas configurações que precisam ser contextualizadas nos tempos e espaços que as produzem,

[...] considerando a ação dos sujeitos que as organizam e fazem circular interesses e necessidades de classes, de grupos, de instituições e de projetos políticos capazes de constituir e reconstituir os sentidos de pertencimento humano e social. (LINHALES, 2006, p. 93-94).

Movimento, Porto Alegre, v. 16, n. 01, p. 209-225, janeiro/março de 2010. 
214 Artigos Originais Isabel C. Martines e Sérgio R. C. Junior

Ainda conforme Linhales:

Como é sabido, as práticas esportivas já estavam bastante disseminadas na sociedade brasileira desde o final do século XIX e frequentavam algumas escolas como conteúdos curriculares ou como experiências lúdicas, prescritas por professores ou trazidas pelos próprios alunos para os momentos de recreio. [...] Todavia, a pesquisa em curso permite sugerir que é posteriormente a 1920 que essa prática social emprestará decisivamente à escola os seus dotes modernos e, nesse processo, também receberá dela sua forma socializadora. É também essa trama que cria as condições que possibilitarão que o esporte passe a ser, cada vez mais, apresentado como conteúdo educativo e como prática. Um ingrediente do fazer escolar (LINHALES, 2006, p 95).

Mesmo separado cronologicamente por alguns anos, o objeto de análise da autora e o objeto em questão neste artigo vão ao encontro do entendimento de que o esporte - que já se fazia presente na sociedade brasileira - começa a ser apresentado como uma prática escolar ou como um "ingrediente do fazer escolar", assumindo então um lugar de destaque entre a juventude estudantil.

É nesse contexto que alunos e professores do CEP passam a incorporar o esporte no conjunto de suas ações e as práticas e competições esportivas entre os estudantes secundaristas parecem ampliar-se a cada edição das Olimpíadas Colegiais, já denotando certa importância do evento no cenário paranaense. A seguir, as palavras do aluno Luiz Cardoso, veiculadas no jornal dos estudantes, sobre as Olimpíadas de 1940, indicam-nos uma possível interpretação da grandiosidade do certame:

\footnotetext{
Esta competição, que foi a maior e a mais importante que se efetuou nos meios colegiais, despertou desusado entusiasmo entre os estudantes paranaenses que batalharam com denodo pelos louros olímpicos. [...] No dia da abertura solene, tivemos a surpresa de ver presentes os representantes do Sr. Prefeito, do Dr. Hostílio de Araújo, digno Diretor Geral da Educação, e o Sr. ten. cel. Dimas S. de Menezes, comandante da $3^{\text {a }}$ R.A.M. e outras altas autoridades civis e militares (O GINÁSIO..., 1940, p.11).
}

Movimento, Porto Alegre, v. 16, n. 01, p. 209-225, janeiro/março de 2010. 
Podemos perceber que as Olimpíadas Colegiais começavam a se configurar como um importante evento esportivo estudantil, a ponto de contar com a participação de instituições de ensino de diferentes municípios e com a presença de autoridades políticas, civis e militares nas solenidades.

No entanto, apesar da crescente importância atribuída à competição, entre os anos 1941 e 1945 as Olimpíadas não foram realizadas. As fontes consultadas não trazem informações suficientes para um entendimento dos motivos que levaram à interrupção do evento.

Somente a partir de 1946 as competições esportivas envolvendo instituições escolares do Paraná voltaram a ser promovidas, com a realização da Olimpíada do Centenário, alusiva aos 100 anos de fundação do Colégio Estadual do Paraná. Tal evento foi proposto e organizado pelo CEP, de acordo com as determinações da Portaria n..$^{\circ} 924$, de 28/06/1946, da Diretoria Geral de Educação, a qual procurava "incentivar a prática da educação física e dos desportos dentre a mocidade estudantil dos Estabelecimentos de Ensino Secundário do Estado".

De 1946 em diante, as Olimpíadas Colegiais e Ginasiais ${ }^{5}$ passaram a contar com a participação das equipes masculinas e femininas ${ }^{6}$ de diversos estabelecimentos de ensino secundário da capital e de cidades do interior. O desenvolvimento do evento estava relacionado à crescente valorização da prática esportiva na sociedade paranaense, manifesto inclusive no suporte oferecido pelo poder público para a efetivação das Olimpíadas. Abaixo, segue a transcrição de um trecho do Regulamento das Olimpíadas, que nos apresenta algumas informações importantes a esse respeito:

\footnotetext{
${ }^{5}$ Esta nomenclatura aparece a partir de 1946, sendo que o evento também era chamado de Campeonato Colegial e Ginasial ou ainda Jogos Colegiais e Ginasiais, em alguns momentos. O acréscimo do termo "ginasial" está relacionado às denominações do próprio ensino secundário, que entraram em vigor com a Reforma Capanema, em 1942, quando esse nível de ensino passou a ser dividido em ginasial e colegial (sendo este último subdividido em clássico e científico). ${ }^{6}$ Os alunos participantes das Olimpíadas eram divididos segundo a faixa etária: $1^{\text {a }}$ Classe (18 a 21 anos), $2^{\mathrm{a}}$ Classe (16 a 18 anos) e $3^{\mathrm{a}}$ Classe (13 a 16 anos) nas provas de atletismo e natação; Série A (13 a 17 anos) e Série B (17 a 21 anos), nas competições coletivas. As alunas participavam das competições em uma única série ou classe, com idade mínima de 14 anos.
}

Movimento, Porto Alegre, v. 16, n. 01, p. 209-225, janeiro/março de 2010. 
Art. $1^{\circ}$ - A Olimpíada Colegial e Ginasial, será realizada, anualmente, em época oportuna a ser designada pela Secretaria de Educação e Cultura, e em reunião da "Comissão Organizadora", com o objetivo de incentivar a prática da educação física e dos desportos em todas as suas modalidades dentre a mocidade dos Estabelecimentos de Ensino Secundário do Estado, devidamente oficializados.

Art. $2^{\circ}$ - A Olimpíada Colegial e Ginasial, terá o patrocínio oficial do Estado, pela Secretaria de Educação e Cultura, ficando a cidade de Curitiba, Capital do Estado, designada para sede da mesma.

Art. $3^{\circ}$ - A Olimpíada Colegial e Ginasial será organizada e dirigida pelo Departamento de Educação Física do Colégio Estadual do Paraná e por uma "Comissão Organizadora" composta por professores de educação física e dois alunos devidamente credenciados por cada Estabelecimento de Ensino inscrito para a competição (COLÉGIO..., 1946, s/p).

Observando o Regulamento é possível perceber que, contrariamente ao afirmado por Mezzadri (2000), a relação entre instituições escolares, esporte e governo estadual já estava estabelecida mesmo antes da criação da Divisão de Educação Física, no início da década de 1950. Outra questão importante da fonte acima refere-se à presença de professores e alunos das instituições de ensino na organização do evento, o que pode indicar uma continuidade com a estrutura organizacional utilizada nas primeiras versões do evento, nos anos finais da década de 1930.

Nesse contexto, a relação entre o poder público e as competições esportivas estudantis parecia estar sendo intensificada a cada Olimpíada realizada. Além do patrocínio oficial, diversas autoridades participavam das aberturas solenes e demais cerimônias de premiação. Cabe ainda o registro de que os troféus entregues aos vencedores das competições, a partir de 1946, foram designados com nomes de políticos e representantes civis e militares da época.

Para além dessa questão, também é notório o considerável aumento dos participantes, ano após ano. A citação abaixo, sobre a Olimpíada Colegial e Ginasial de 1952, nos dá mostras desse crescimento:

Movimento, Porto Alegre, v. 16, n. 01, p. 209-225, janeiro/março de 2010. 


\begin{abstract}
Como todos os anos, realizar-se-á em nossa capital, de 31 de agosto a 7 de setembro, mais uma Olimpíada Colegial e Ginasial, sob o patrocínio oficial do Estado, por intermédio da Secretaria de Educação e Cultura. Os Jogos Colegiais e Ginasiais deste ano revestir-seão de invulgar brilhantismo devido ao grande número de delegações participantes que são as seguintes inscritas até o momento: Jacarezinho, Londrina, União da Vitória, Bandeirantes, Santo Antônio da Platina, Palmas, Palmeira, Ponta Grossa. Pelo Instituto de Educação: Cambará, Foz do Iguaçu, Rolândia, Arapongas, Piraí do Sul, Jaguariaíva, Wenceslau Braz e Siqueira Campos (O COLÉGIO...., 1952, p. 9).
\end{abstract}

Como visto até aqui, chegamos em 1952 com a participação de um grande número de estabelecimentos de ensino de diversos municípios nas Olimpíadas Colegiais e Ginasiais e o apoio governamental para a realização dos certames já estava bastante evidenciado. Portanto, o que de fato faz com que o ano de 1953 seja considerado por muitos como o ano que marca o início das competições esportivas entre os estudantes do Paraná? E, mais do que isso, o que diferencia as Olimpíadas de 1953 de todas as outras realizadas anteriormente? É sobre isso que falaremos a seguir.

\title{
3 A OlimpíADA DE 1953: A GÊNESE DE UM EVENTO ESPORTIVo?
}

Não nos restam dúvidas de que as Olimpíadas Colegiais de 1953 receberam uma especial atenção, particularmente do Governo do Estado. De fato, o evento realizado nesse ano é considerado "oficialmente" como a primeira edição das competições esportivas estudantis. Ao buscarmos compreender o que diferencia o evento de 1953 das demais Olimpíadas que haviam sido realizadas até então, há que se considerar que o evento esportivo estudantil desse ano está inserido em um contexto particularmente diferente ao que estava estabelecido nos anos anteriores.

No ano de 1953, foi comemorado o Centenário da Emancipação Política do Estado do Paraná. Os anos que antecederam a data foram representados pela visibilidade de um projeto de modernização da capital Curitiba, com o objetivo de construir e afirmar um centro admi-

Movimento, Porto Alegre, v. 16, n. 01, p. 209-225, janeiro/março de 2010. 
nistrativo no Paraná (TRINDADE; ANDREAZZA, 2001). A maioria das obras foi inaugurada nos anos iniciais da década de 1950, certamente pela alusão às comemorações do referido centenário. Dentre as obras realizadas para a afirmação deste "local de poder", podemos citar o Palácio do Governo, Palácio da Justiça, Tribunal Eleitoral, Comissões da Assembleia, Teatro Guaíra, Biblioteca Pública, as avenidas de acesso ao Centro Cívico, Praça do Centenário e Monumento do Centenário (MAGALHÃES, 2001).

Tendo em vista esse contexto, torna-se possível afirmar que a edição de 1953 das Olimpíadas Colegiais e Ginasiais ${ }^{7}$ segue a mesma lógica: a busca pela construção de um "lugar de poder" e afirmação da "modernização" do estado e, em especial, da capital. Um dos indicadores desta constatação é que, segundo as fontes, a Olimpíada de 1953 foi organizada para ser uma das "festividades comemorativas do ano do Centenário", "uma grande competição entre todos os colégios e ginásios do estado", "o maior certame colegial do estado", "uma verdadeira olimpíada colegial", "um magno certame estudantil com todos os esportes" (GAZETA DO POVO, 1953b). Os esportes em questão eram natação, atletismo, voleibol, basquetebol e futebol, disputados nas categorias definidas pela idade dos competidores, apresentadas anteriormente.

Contudo, por mais representativo que tenha sido o evento, a interpretação histórica que atribui o pioneirismo dos Jogos Colegiais à edição de 1953 pode ser facilmente refutada, a partir de alguns indícios, como os que seguem abaixo:

Os JOGOS COLEGIAIS DO PARANÁ, frisamos, constituem-se já ao nono ano consecutivo de sua realização, um espetáculo de gala e esplendor raros, num desses acontecimentos que se constituem em tradição, cuja renovação anual passa a figurar no "carnet" dos sonhos e dos anseios da mocidade que frequenta nossos estabelecimentos de ensino de nível secundário (GAZETADO POVO, 1953b, p. 9, grifos no original).

A OLIMPÍADA COLEGIAL já ganhou tradição. Já atingiu a maturidade. Em nove anos de experiências favoráveis, já veio demonstrar que é, de fato, um gran-

Movimento, Porto Alegre, v. 16, n. 01, p. 209-225, janeiro/março de 2010. 


\begin{abstract}
dioso e grato acontecimento. Organizá-la sempre melhor, mais espetacular, dispensar-lhe sempre maior apoio, maior colaboração, é a obra de verdadeiro, de legítimo patriotismo (id., grifos no original).

Com êxito notável foram encerrados os IX JOGOS COLEGIAIS DO PARANÁ, essa magnífica e notável realização que centralizou em nossa capital cerca de dois mil atletas colegiais de todo o Estado. (GAZETA DO POVO, 1953b, p. 10, grifos no original).
\end{abstract}

Neste sentido, devemos nos atentar para o fato de que um evento, que marca os festejos de um importante acontecimento político, não necessariamente pode ser tratado como o primeiro de seu gênero, por mais que tenham sido substancialmente ampliadas as suas proporções, pois participaram em 1953, sob a chancela do governo do estado, todas as instituições de ensino do Paraná.

O fato de se trazer alunos de todos os colégios paranaenses à capital e assinalar como sendo "a primeira" uma edição de um evento que já existia há alguns anos, certamente possui uma intenção, pois, como nos aponta Bourdieu (1994), todas as realizações pressupõem necessariamente uma gama de interesses, que podem ser os mais diversos. Com isso, não são possíveis os discursos desinteressados e ingênuos, já que não existe neutralidade nas realizações.

A partir dessa premissa, emerge a ideia de que as ações efetivadas em 1953 são decorrentes da intenção do Governo do Paraná de afirmar uma identidade paranaense, o que incluía também a criação de uma identidade esportiva entre a juventude estudantil e a realização da "primeira" competição esportiva entre os estudantes paranaenses.

Além dos indícios apresentados até aqui, outro fator nos permite afirmar que as Olimpíadas de 1953 foram pensadas para compor um projeto político bastante específico naquele momento. Nos anos seguintes, todo o fervor demonstrado pelo governo do estado pelo evento parece enfraquecer e o esporte já não figura entre os principais interesses do poder público. Após as celebrações do Centenário de Emancipação Política do Estado e as realizações em diversas áreas, os investimentos na competição estudantil diminuíram substancialmente. Nas palavras de Camilo Nepomuceno, aluno que frequentemente escrevia

Movimento, Porto Alegre, v. 16, n. 01, p. 209-225, janeiro/março de 2010. 
no periódico do CEP, percebemos a falta de pomposidade do evento de 1954:

Como todos os anos acontece, realizou-se uma vez mais, na Semana da Pátria, em nosso Colégio, as OLIMPÍADAS COLEGIAIS DO PARANÁ, décima competição desse gênero realizada neste Estado. [...] Devido a motivos de força maior, as representações do interior não conseguiram vir a esta capital, como das outras vezes, para disputarem juntos aos estabelecimentos de ensino de nossa cidade, dos quais também faltaram vários. Assim, apenas oito delegações tomaram parte no prélio desse ano. (O COLÉGIO..., 1954b, p. 2, grifos no original).

No mesmo ano, Hélcio Buck Silva, ${ }^{7}$ em matéria publicada na Gazeta do Povo, apresenta em tom incisivo algumas questões importantes para nossa análise:

Os Jogos Colegiais de 1954 não tiveram a pompa e o brilho que caracterizaram os Jogos dos outros anos. Os Colégios do interior ficaram à margem dos acontecimentos desportivos, pois o nosso Governo não dispunha de verba para conduzir e alojar os jovens interioranos à festa máxima da juventude colegial. Retrocedemos neste particular; o entusiasmo, a galhardia dos outros anos, quando aqui estiveram quase todos os colégios do interior paranaense, não foram o bastante para que o atual Governo fornecesse auxílio financeiro numa obra de intercâmbio estudantil e aprimoramento de nossa raça. Lá ficaram aqueles meninos que talvez por anos vêm sonhando em conhecer a capital do Estado. Filhos de lavradores, gente a quem devemos o progresso de nosso Estado (GAZETA DO POVO, 1954, p. 9).

Já no ano de 1955, em matéria intitulada Jogos Olímpicos, as seguintes palavras foram impressas:

Passou o tempo. Veio 1954. A tristeza estampavase em todos os rostos. Apenas competições entre os

\footnotetext{
${ }^{7}$ Segundo apresentação do próprio periódico, Hélcio Buck Silva era "professor de Educação Física e atleta consagrado no âmbito internacional", por ter representado o Brasil nos Jogos Olímpicos de Helsinque, em 1952, na modalidade do Salto com Vara. Hélcio foi aluno do CEP nas décadas de 1930 e 1940 e, após frequentar curso de formação específica, tornou-se professor de Educação Física da instituição (CHAVES JUNIOR, 2004).
}

ovimento, Porto Alegre, v. 16, n. 01, p. 209-225, janeiro/março de 2010. 
colégios da Capital. Notava-se a falta imensa que faziam as delegações do interior. Veio 1955. Novamente aproxima-se Setembro. Novamente sabemos que uma vez mais deixarão as entidades do interior de participar deste magno certame. Mas, consolamo-nos, sabendo que os atletas dos Colégios da Capital tudo farão para sanar a imensa falta que fazem os valores de fora, que com aquela tradicional rivalidade "bairrista" tanto contribuíam para dar maior colorido às competições. (O COLÉGIO..., 1955, p. 9, grifos no original).

São várias as questões que poderiam ser analisadas a partir das passagens acima. Desde o discurso que atribui ao esporte um papel central no aprimoramento da raça, tão comum à época, à crítica da falta de investimentos e até mesmo o alcance do progresso para as regiões interioranas do estado. Porém, nossa intenção é apresentar, a partir dos indícios, como os eventos esportivos estudantis provavelmente foram tratados naqueles tempos.

Particularmente, interessa-nos compreender que houve uma clara intenção governamental em marcar uma "ruptura" com o que vinha sendo realizado até então. Assim como foram arquitetadas e concretizadas diversas construções de "lugares de poder", em alusão ao "espírito moderno" que embalava as comemorações do Centenário de Emancipação Política, o esporte e, em especial, a competição estudantil em questão, parece ter sido utilizada como um instrumento para tornar esse projeto mais nítido. Toda a logística e infraestrutura montadas para o evento de 1953 chamavam a atenção, mas nos anos seguintes, para os entusiastas do esporte, restou a lamentação do corte dos investimentos.

A partir do exposto até aqui, podemos dizer que os trabalhos que apontam para o início dos Jogos Colegiais em 1953 certamente privilegiaram, sobretudo, as "fontes oficiais", atendo-se à versão governamental que, por sua vez, buscou registrar na história os acontecimentos de acordo com seus próprios interesses, desconsiderando as edições anteriores dos Jogos que já haviam sido organizadas pelo próprio poder público, por professores e alunos do CEP e demais instituições de ensino que faziam parte das Comissões Organizadoras dos jogos.

Movimento, Porto Alegre, v. 16, n. 01, p. 209-225, janeiro/março de 2010. 


\section{CONSIDERAÇÕES FINAIS}

Buscando respostas para as indagações apresentadas no início do trabalho, o diálogo com as fontes nos possibilita afirmar que as Olimpíadas Colegiais, iniciadas em 1938, e os Jogos Colegiais do Paraná, "oficialmente" iniciados em 1953, representam a mesma competição esportiva entre estudantes paranaenses, porém com atribuições e significados diferentes ao longo dos anos.

Entender a história significa compreendê-la como a síntese entre continuidades e rupturas. No caso dos Jogos Colegiais, a continuidade é representada pela tradição do evento, verificada a partir das fontes consultadas. A ruptura, pela intenção governamental em tentar marcar na história um evento representativo como sendo o pioneiro, em decorrência dos interesses em jogo. Na tentativa de apresentar uma outra versão da história das práticas e competições esportivas nas escolas paranaenses, entendemos que é importante confrontar uma determinada interpretação oficial da história com a análise de fontes até então não privilegiadas que podem nos mostrar que a produção de uma interpretação oficial nem sempre se aproxima do que realmente possa ter acontecido.

Além disso, não é somente o início do evento que traz algumas questões a serem melhor exploradas. As edições sequentes dos Jogos também indicam determinadas particularidades como, por exemplo, a suspensão dos Jogos Colegiais durante certa gestão governamental (1998-2002) e sua retomada na gestão seguinte com grandioso destaque. Mas essa é outra história, repleta de continuidades e rupturas, que precisa ainda de muito trabalho para ser compreendida.

Movimento, Porto Alegre, v. 16, n. 01, p. 209-225, janeiro/março de 2010. 


\begin{abstract}
The history of a sporting event between continuity and ruptures: the Olimpiadas Colegiais and the Jogos Colegiais do Paraná (1938-1953).

Abstract: This article intends to discuss a version of history that indicates the emergence of Jogos Colegiais do Paraná in the beginning of the 1950's, confronting the relationship of that event with the Olimpiadas Colegiais e Ginasiais, promoted by Colégio Estadual do Paraná since the ends of the 1930's. The central hypothesis of this paper is the sportive competitions, which were already present in schools, received great attention in 1953, because of a series of policy configurations, trying to build a place of power and a sports identity by the state government.

Keywords: Sports. History. Physical Education
\end{abstract} nuidad y rupturas: las Olimpíadas Colegiais y los Jogos Colegiais do Paraná (1938-1953).

Resumen: El presente artículo pretende cuestionar determinada versión de la historia que indica la aparición de los Jogos Colegiais do Paraná a principios de los años 1950, confrontando la relación de estos juegos con las Olimpíadas Colegiais e Ginasiais, promovidas por el Colégio Estadual do Paraná desde el final de la década de 1930. La hipótesis central del estudio es que las competiciones deportivas, que ya estaban presentes en las escuelas, recibieron gran atención en 1953 , debido a una serie de configuraciones de la política, tratando de construir un lugar de poder y una identidad deportiva por el gobierno estatal.

Palabras clave: Deportes. Historia. Educación Física.

\section{REFERÊNCIAS}

BOURDIEU, Pierre. Sociologia. São Paulo: Ática, 1994.

CHAVES JUNIOR, Sergio Roberto. A Educação Física do Ginásio Paranaense ao Colégio Estadual do Paraná: contribuições para a construção de uma história de uma disciplina escolar (1931-1951). 2004. 216 f. Dissertação (Mestrado). Programa de Pós-Graduação em Educação, Setor de Educação, UFPR, Curitiba, 2004.

COLÉGIO ESTADUAL DO PARANÁ. Departamento de Educação Física. Relatório e Regulamento da Olimpíada Colegial e Ginasial de 1946 - Olimpíada do Centenário. Curitiba, 1946.

Movimento, Porto Alegre, v. 16, n. 01, p. 209-225, janeiro/março de 2010. 
224 Artigos Originais Isabel C. Martines e Sérgio R. C. Junior

Relatório e Regulamento da II Olimpíada Colegial e Ginasial de 1947. Curitiba, 1947.

Relatório e Regulamento da III Olimpíada Colegial e Ginasial de 1948. Curitiba, 1948

Relatório e Regulamento da Olimpíada Colegial e Ginasial de 1951. Curitiba, 1951.

GAZETA DO POVO. Campeonato Ginasial e Colegial. Curitiba, v.35, n.10.017, 28 ago. 1953a. 10 set. $1953 b$

Os Jogos Colegiais alcançam a maturidade. Curitiba, v.35, n.10.026,

Atletismo nos Jogos Colegiais. Curitiba, v. 36, n. 10.331, 18 set. 1954

LINHALES, Meily A. A Produção de Uma Forma Escolar Para o Esporte: Os Projetos Culturais da Associação Brasileira de Educação (1926-1935) Como Indícios para a Historiografia da Educação Física. In: OLIVEIRA, Marcus Aurélio Taborda de. (Org.). Educação do Corpo na Escola Brasileira. Campinas: Autores Associados, 2006. p. 93-110.

MAGALHÃES, Marion B. Paraná: Política e Governo. Curitiba: SEED, 2001.

MARTINES, Isabel Cristina. Jogos Colegiais do Paraná: das políticas públicas ao chão da escola. 2007. 80f. Monografia (Especialização Lato Sensu). Curso de Especialização em Educação Física Escolar, Departamento de Educação Física, UFPR, Curitiba, 2007.

MARTINS, Dílson José. A Formulação e a implementação das políticas públicas no campo do esporte no estado do Paraná entre 1987 e 2004. 2004. 266 f. Dissertação (Mestrado). Curso de Mestrado em Educação Física, Departamento de Educação Física, UFPR, Curitiba, 2004.

MEZZADRI, Fernando M. A estrutura esportiva no Estado do Paraná: da formação dos clubes às atuais políticas governamentais. 2000. 169f. Tese (Doutorado). Programa de Pós-Graduação em Educação Física, Faculdade de Educação Física, Unicamp, Campinas, 2000.

NUNES, Clarice. O "velho" e "bom" ensino secundário: momentos decisivos. Revista Brasileira de Educação: 500 anos de educação escolar, Campinas, n. 14, p. 35-60, Maio/Ago, 2000.

O COLÉGIO ESTADUAL DO PARANÁ. As Olimpíadas Colegiais. Curitiba, v. 10 n. 38 , set. 1948 .

As Olimpíadas Colegiais. Curitiba, v.11, n. 51, ago/set, 1951.

Olimpíadas Colegiais. Curitiba, v.12, n. 58, ago. 1952.

A Nossa Olimpíada. Curitiba, v.13, n. 66, set, 1953.

Movimento, Porto Alegre, v. 16, n. 01, p. 209-225, janeiro/março de 2010. 
Como surgiram nossas Olimpíadas? Curitiba, v.14, n. 70, ago. 1954a. Mantido o Tabú Olímpico. Curitiba, v.14, n. 71, set. 1954b. . Jogos Olímpicos. Curitiba, v.15, n. 74, ago. 1955.

O GINÁSIO PARANAENSE-EXTERNATO. Salve $3^{\text {a }}$ Olimpíada Colegial. Curitiba, v.2, n. 9-10, out./nov. 1940 .

STRAUBE, Ernani Costa. Do Licêo de Coritiba ao Colégio Estadual do Paraná. Curitiba: FUNDEPAR, 1993.

THOMPSON, Edward Palmer. A miséria da Teoria. Rio de Janeiro: Zahar, 1981.

TRINDADE, Etelvina Maria de Castro; ANDREAZZA, Maria Luiza. Cultura e Educação no Paraná. Curitiba: SEED, 2001.

Pesquisa financiada pela CAPES

Recebido em: 11.01.2009

Aprovado em: 23.07.2009

Movimento, Porto Alegre, v. 16, n. 01, p. 209-225, janeiro/março de 2010. 